\title{
LEVANTAMENTO DAS CONDIÇÖES GERAIS DE PONTES DA RN 118 - TRECHO ENTRE CAICÓ/RN E JUCURUTU/RN
}

\author{
LIMA MORAIS, IGOR \\ Estudante \\ Universidade Federal Rural do Semi-Árido \\ Rio Grande do Norte; Brasil \\ E-mail: igor123lm@hotmail.com
}

\author{
VIEIRA DA NÓBREGA, MARCILENE \\ Professora Doutora do Magistério Superior \\ Universidade Federal Rural do Semi-Árido \\ Rio Grande do Norte; Brasil \\ E-mail: marcilenenobrega@ufersa.edu.br
}

\author{
KLEYCE DA SILVA GÓIS, ALEXSANDRA \\ Estudante \\ Universidade Federal Rural do Semi-Árido \\ Rio Grande do Norte; Brasil \\ E-mail: kleycinha14@hotmail.com
}

\section{RESUMO}

Pontes são estruturas que surgiram com o intuito de suprir as necessidades das populações, interligando pontos distintos por estruturas seguras. No decorrer dos anos, as pontes de concreto armado ganharam espaço na construção civil por possuírem boa resistência à compressão e terem vida útil considerável. Porém, sem uma manutenção e acompanhamento dessas estruturas, há o surgimento de manifestações patológicas que acarretam na degradação do material. Partindo dessa ideia, esse artigo teve como objetivo principal realizar um levantamento do estado de uso em pontes existentes no trecho de da Rodovia RN 118 compreendidas entre as cidades de Caicó e Jucurutu. Para tanto, foram realizadas inspeções visuais, com posterior relatório fotográfico, a fim de observar a presença ou não de manifestações patológicas. Além disso, foi identificado o local onde cada uma das pontes está inserida. Após a análise desses dados obtidos, foi possível constatar uma grande incidência de manifestações patológicas, principalmente na superestrutura das obras de arte, muitas dessas podendo ser causadas pela ausência de vistorias periódicas, falhas de projeto e erros de execução. Diante dos resultados encontrados, foram identificados prováveis agentes agressivos, que acarretam em prejuízos na vida útil da estrutura.

Palavras-chave: Pontes. Concreto Armado. Manifestações Patológicas.

\section{ABSTRACT}

Bridges are structures that emerged in order to meet the needs of populations, connecting distinct points by safe structures. Over the years, reinforced concrete bridges have gained ground in construction because of their good compressive strength and considerable service life. However, without a maintenance and monitoring of these structures, there is the emergence of pathological manifestations that lead to the degradation of the material. Based on this idea, this article had as its main objective to carry out a survey of the state of use on existing bridges along the RN 118 highway between Caicó and Jucurutu. Therefore, visual inspections were made, with subsequent photographic report, in order to cover the presence of pathological manifestations. Besides that, it was characterized the place where each bridge is inserted, identifying the aggressiveness of the environment. After analyzing these data, it was possible to verify a high incidence of pathological manifestations, mainly in the superstructure of the artworks, many caused by the absence of periodic inspections, design failures and execution errors. Based on the results found, probable aggressive agents were identified which cause losses in the useful life of the structure.

Keywords: Bridges. Reinforced concrete. Pathological Manifestations.

\section{INTRODUÇÃO}

O Brasil possui a conjuntura de dominância do transporte rodoviário com as principais rotas logísticas do país, além disso, apresenta uma das mais amplas, diversificadas e extensas redes fluviais de todo o mundo. Atrelando esses fatores têm-se a necessidade de inúmeras pontes, que atuam compondo a integração entre as comunidades e o crescimento do país, auxiliando na transposição de pessoas, veículos e mercadorias.

Segundo Marchetti (2017), ponte é uma obra construída com o intuito de permitir a continuidade de uma via qualquer, ligando pontos não acessíveis, separados por um curso de água ou qualquer depressão do terreno. Porém, não podemos 
ater-se apenas a função de ligar duas margens opostas, ela precisa estar integrada à paisagem de modo a proporcionar um efeito visual agradável. Sendo assim, não por acaso, são chamadas no meio técnico de obras de artes especiais.

As pontes podem ser classificadas de acordo com os materiais utilizados em sua construção. Segundo Marchetti (2017), classificam-se nos seguintes tipos: pontes de madeira, de aço, de alvenaria, de concreto simples, armado ou protendido. O estudo desse trabalho dará ênfase as pontes em concreto armado.

Com o avanço da tecnologia e o desenvolvimento de novos materiais, as estruturas de concreto tornaram-se mais duráveis, sendo determinados atender critérios normativos. Essas estruturas, a união do concreto com a armadura de aço, proporcionam resistência às tensões de compressão e tração devido às características dos dois materiais. Porém, esse material está sujeito a alterações ao longo do tempo, em função de interações entre os elementos que o constituem.

A falta de manutenção nas rodovias e em suas obras de artes tornou-se evidente no Brasil, mas especificamente quando diz respeito às obras de âmbito estadual. A rodovia estadual RN 118, localizada no estado do Rio Grande do Norte, tem um tráfego intenso de veículos pesados, visto que a rodovia é de grande importância logística para a região, ligando o Seridó, Vale do Açu e Oeste do Estado do Rio Grande do Norte, além de ser utilizada diariamente por moradores das cidades vizinhas. Esse volume intenso de veículos causa um grande desgaste nas pontes presentes na rodovia, ainda mais pelo fato de serem obras antigas e não terem sido projetadas para as condições de tráfego atuais.

Apesar de considerar-se que, de modo geral, essas obras têm dado verdadeiros exemplos de grande durabilidade, muitas vezes, em condições adversas, convém lembrar que elas não têm vida útil infinita. Pontes, assim como as demais estruturas, estão sujeitas aos efeitos de eventos externos e adquiridos durante sua vida útil, que dependendo de sua natureza e intensidade podem vir a afetar o seu comportamento estrutural. Segundo Bertolini (2014), o concreto armado é um material pouco resistente à tração, por isso as trincas e fissuras são comuns nesse tipo de estrutura. Sendo assim, se faz necessário um processo mais amplo de gestão dessas obras de artes, compreendendo inspeções periódicas de forma a avaliar o seu estado de conservação, antecipando possíveis problemas e detectando quando uma estrutura se encontra deteriorada, sempre em busca de garantir a segurança da população que trafega nessas estruturas.

Portanto, o presente trabalho foi desenvolvido com o objetivo de verificar as condições gerais das pontes da RN 118, compreendidas entre as cidades de Caicó e Jucurutu. Especificamente será feita também a caracterização geométrica das pontes com medições de suas dimensões básicas e de técnica construtiva utilizada em sua construção; realizar os levantamentos dos problemas existentes, levantando as possíveis anomalias, suas causas e propondo reparos nessas obras de arte.

\section{DESENVOLVIMENTO}

\subsection{Fundamentação Teórica}

Segundo Marchetti (2017), o termo ponte é denominado para a obra que tem o intuito de permitir a continuidade de uma via qualquer, ligando pontos não acessíveis, separados por um curso de água ou qualquer depressão do terreno. Em geral, as pontes são compostas por três regiões estruturais: a superestrutura, a mesoestrutura e a infraestrutura. Na figura 1 é possível observar esses elementos.

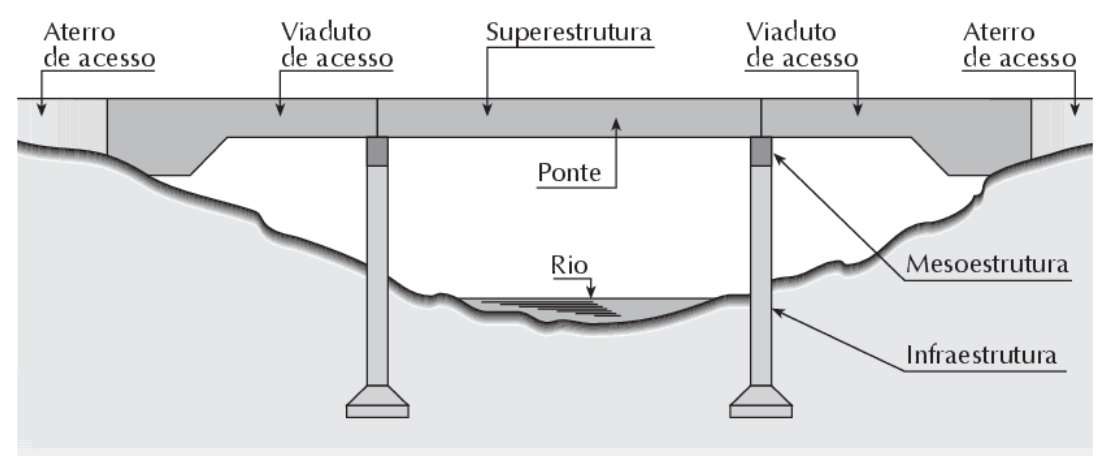

Figura 1: Elementos estruturais da ponte. Marchetti (2017). 


\subsection{Elementos Constituintes das Pontes}

Segundo o Manual do Instituto de Pesquisas Rodoviárias do Departamento Nacional de Infraestrutura de Transportes IPR DNIT 709, a superestrutura abrange todos os elementos estruturais situados acima dos apoios, tendo os seguintes componentes básicos: o estrado (prolongamento físico da rodovia), os elementos principais (elementos estruturais longitudinais) e os elementos secundários (elementos estruturais transversais).

Debs e Takeva (2009) subdividem a superestrutura em duas partes: principal e secundária. Levando em consideração a seção transversal, os elementos da superestrutura são a pista de rolamento, o acostamento, passeios de pedestres, guarda-corpo e guarda-roda.

Com relação a seção transversal, conforme ilustrado na figura 2, tem-se descritos os principais elementos constituintes:
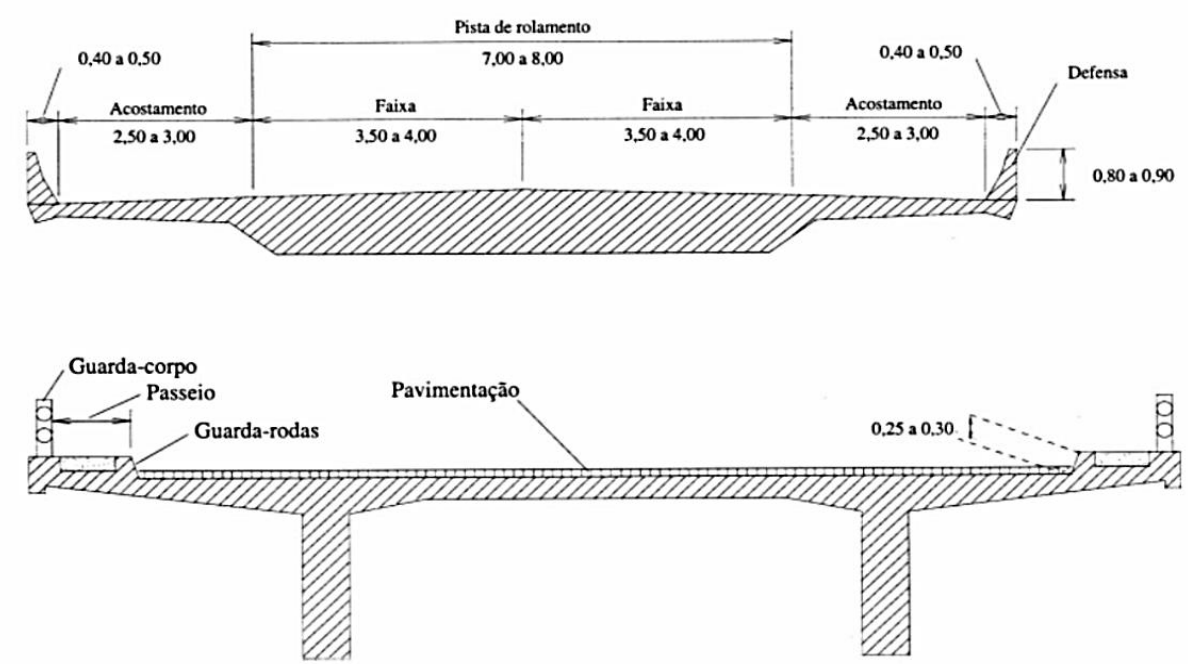

Figura 2: Elementos constituintes da seção transversal da superestrutura. Debs e Takeya (2009).

$\mathrm{Na}$ figura observa-se a pista de rolamento, considerada a largura disponível para o tráfego normal dos veículos, que pode ser subdividida em faixas reservadas; tem-se também o acostamento que é a largura adicional à pista de rolamento destinada à parada, por parte dos veículos, em casos de emergência., além de ser usada para circulação de pedestres e bicicletas quando não há local apropriado para esse fim; vê-se também o passeio de pedestres consideradas as parte do tabuleiro destinadas ao tráfego de pedestres; o guarda corpo, que de acordo com o IPR DNIT 709 (2004) é um elemento de proteção planejado para garantir a segurança dos usuários das pontes. Nas pontes rodoviárias são normalmente de concreto armado, variando de $0,75 \mathrm{~m}$ a $1,10 \mathrm{~m}$.; há o guarda rodas, elemento destinado a impedir a invasão dos passeios pelos veículos que trafegam na via; as junta de dilatação, que são componentes construtivos criados com o intuito de permitir a movimentação provocada pela variação de temperatura, retração e fluência do concreto, e a flexibilidade da obra em que está inserida; o sistema de drenagem, dispositivo criado visando o escoamento adequado das águas superficiais, com inclinações nos sentidos transversais e horizontais, direcionando-as aos sistemas de captação, evitando o acúmulo de água sobre a pista; por último os aparelhos de apoio que, segundo o IPR DNIT 704, é um dispositivo que faz a transição entre a superestrutura e a mesoestrutura, ou a infraestrutura, tendo como funções principais como a de transmitir as cargas de um elemento para o outro, assim como permitir os movimentos longitudinais da superestrutura devidos à retração própria do elemento e aos efeitos da temperatura, expansão e retração.

\subsection{Principais Anomalias em Pontes}

De acordo com Helene (1992), a patologia pode ser entendida como a parte da engenharia que estuda os sintomas, mecanismos, as causas e origens dos defeitos das construções civis, ou seja, é o estudo das partes que compõem o diagnóstico do problema.

Para Piancastelli (1997), o concreto armado está sujeito a alterações ao longo do tempo, em função de interações entre os elementos que o constituem, com os aditivos e com agentes externos. Frequentemente, dessas interações resultam anomalias, que, geralmente, comprometem o desempenho da estrutura, gerando também efeito estéticos indesejáveis. O 
manual IPR DNIT 709 cita as principais causas das patologias que podem ocorrer nas estruturas de concreto. Elas serão detalhadas a seguir:

\subsubsection{Fissuração}

Segundo Curcio (2008), as fissuras, são o tipo mais comum de manifestações patológicas em estruturas, e denominamse pequenas fendas que surgem nas estruturas de concreto, podendo ser inevitáveis, em virtude de tensões provocadas pela flexão, força cortante, torção e restrições à movimentação.

Segundo a norma de impermeabilização (NBR 9575:2003) as fissuras podem ser classificadas por suas dimensões. Na tabela 1, são apresentadas as dimensões das fissuras.

Tabela 1: classificação dos tipos de abertura. Adaptado NBR 9575:2003.

\section{TIPOS DE ABERTURA}

\section{DIMENSÕES (mm)}

\begin{tabular}{|l|l|}
\hline Microfissuras & Menor que 0,05 \\
\hline Fissuras & Até 0,5 \\
\hline Trincas & 0,5 a 1,0 \\
\hline
\end{tabular}

A fissuração em estruturas de concreto pode ser motivada por diversos fatores. No concreto endurecido, pode ser originada por retração - ocorre por conta da redução de volume causada pela diminuição de umidade no concreto - por secagem, por movimentação térmica precoce ou por corrosão das armaduras. Ainda, há as fissuras de origem estrutural, causadas pelas tensões provocadas pela carga permanente e móvel, são elas: fissuras de flexão, de força cortante e de torção.

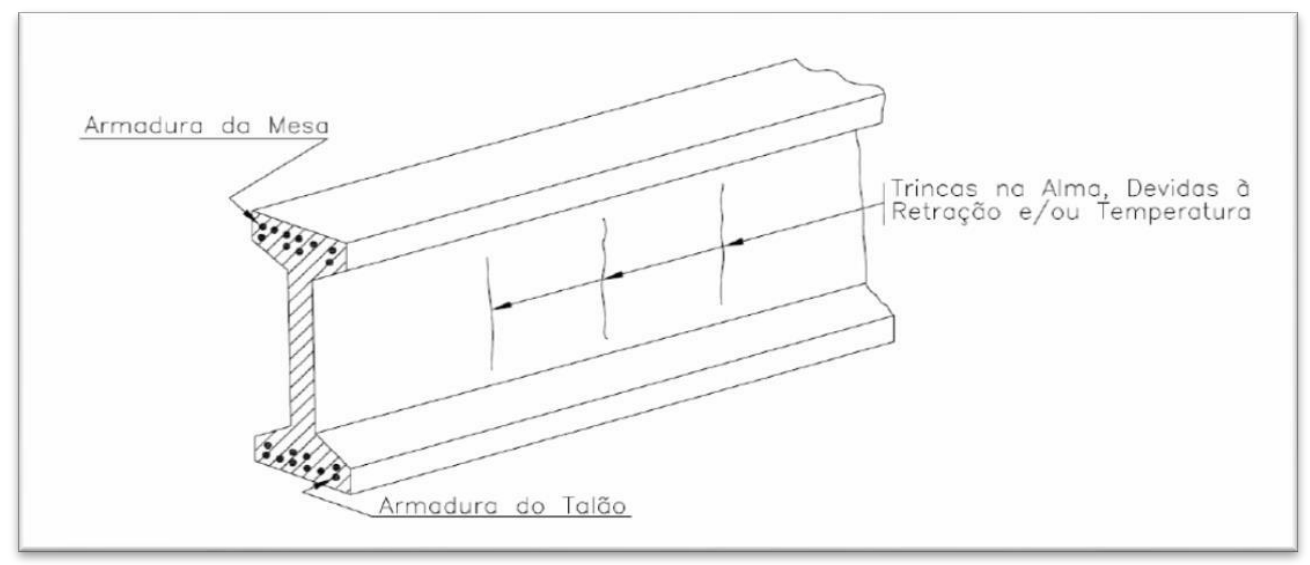

Figura 3: fissuras causadas pela retração do concreto. IPR DNIT 744 (2010).

\subsubsection{Corrosão das Armaduras}

O IPR DNIT 744 (2010) define esse fenômeno como essencialmente químico, que ocorre pela reação da pasta de cimento com alguns elementos químicos, provocando a dissolução do ligante ou a formação de compostos expansivos, que são fatores de deterioração do concreto.

Souza e Ripper (1998) caracterizam a corrosão das armaduras como sendo a deterioração da camada passivante localizada ao redor da superfície das barras. Sendo esta película formada pelo impedimento da dissolução do ferro, devido à alta alcalinidade da solução aquosa existente no concreto.

Betolini (2014) diz que essa reação química é oriunda da reação de carbonatação, que se produz em soluções aquosas através de reações intermediarias. $\mathrm{O}$ autor ainda argumenta que no concreto existe compostos alcalinos presentes nas soluções dos poros ( $\mathrm{NaOH}$ - hidróxido de sódio, $\mathrm{KOH}$ - hidróxido de potássio) que podem vir a reagir quando em contato com o dióxido de carbono que se faz presente na atmosfera. 
Fusco (2008) cita que além do dano causado pela patologia no que diz respeito à resistência mecânica da estrutura, ainda há o agravante de facilitar a penetração de outros agentes nocivos, que podem prejudicar ainda mais as armaduras e o concreto.

\subsubsection{Desagregações}

De acordo com manual do DNIT, a desagregação se inicia na superfície dos elementos concreto por uma mudança de coloração, sendo um sintoma característico da existência de ataque químico. Uma das causas principais das desagregações é a presença de sulfatos e dos cloretos no concreto.

\subsubsection{Disgregações}

Ainda segundo o manual, a disgregação é consequência de fenômenos físicos, como fortes trações localizadas, provocadas por solicitações internas, e substanciais deformações nos elementos estruturais, causadas por sobrecargas anormais. $\mathrm{O}$ fenômeno é caracterizado por rupturas no concreto, especialmente em zonas salientes das peças.

\subsubsection{Carbonatação}

A carbonatação do concreto pode ser definida como um processo físico-químico entre o gás carbônico presente na atmosfera e os compostos do cimento hidratado, transformando-o em carbonatos. O fenômeno provoca uma redução da alcalinidade da solução presente nos poros ao redor das armaduras, facilitando o início da corrosão da armadura e o surgimento de fissuras.

Segundo Neville (2016), esse processo em si não causa a deterioração do concreto armado, mas causa severas consequências entre elas pode-se citar a retração por carbonatação.

\subsubsection{Desgaste superficial}

De acordo com o manual IPR DNIT 709 (2004), o desgaste da superfície do concreto pode ter várias origens, sendo as principais causadas pelo uso continuado nas superfícies sujeitas ao tráfego, assim como por ações abrasivas, como correntezas ou ventos.

\subsubsection{Vazios de Concretagem}

Causados por inadequada vibração e adensamento durante a construção, os ninhos, também conhecidos como vazios de concretagem, são falhas que provocam espaços vagos na estrutura. Em casos mais severos, podem levar à segregação do concreto e expor as armaduras, provocando sua corrosão, ou até mesmo o colapso da estrutura.

\subsubsection{Lixiviação}

Esse fenômeno é causado pelo contato da estrutura com a água, ou seja, durante o processo de hidratação do cimento é formado um composto chamado hidróxido de cálcio - $\mathrm{Ca}(\mathrm{OH}) 2$. Quando esse composto entra em contato com a água, podendo ser dissolvido e carregado para fora da superfície, são formados depósitos de sais que surgem como manchas brancas na estrutura.

\subsubsection{Eflorescência}

De acordo com Neville (2016), a lixiviação dos compostos de calcário pode levar à formação de depósitos de sais na superfície do concreto, conhecidos como eflorescências. Ainda de acordo com o autor, surgem pelo uso inadequado de agregados procedentes de regiões marinhas que não recebem lavagem prévia.

Conforme o IPR DNIT 744 (2010), a eflorescência é o depósito de sais brancos sobre a superfície do concreto, quando uma solução contendo sais vaza através da alvenaria ou concreto e depois evapora.

\subsection{Metodologia}

O levantamento das manifestações patológicas foi realizado através de visitas in loco, com posterior relatório fotográfico. Além disso, foram feitas pesquisas em documentos fornecidos pelo Departamento de Estradas de Rodagens do Rio Grande do Norte - DER RN, e entrevistas com moradores da região.

O trabalho foi realizado nas pontes da rodovia estadual RN 118, dando início na entrada do município de Caicó no 
Estado do Rio Grande do Norte, seguindo até a cidade de Jucurutu - RN. O trajeto entre as duas cidades é de 53,9 Km. Em virtude do tempo para realização deste trabalho foram selecionadas 13 pontes do trajeto, sendo as mesmas com comprimento de até 10 metros. Na figura 4 ilustra-se o trecho da RN 118, com a localização de cada uma das pontes visitadas.

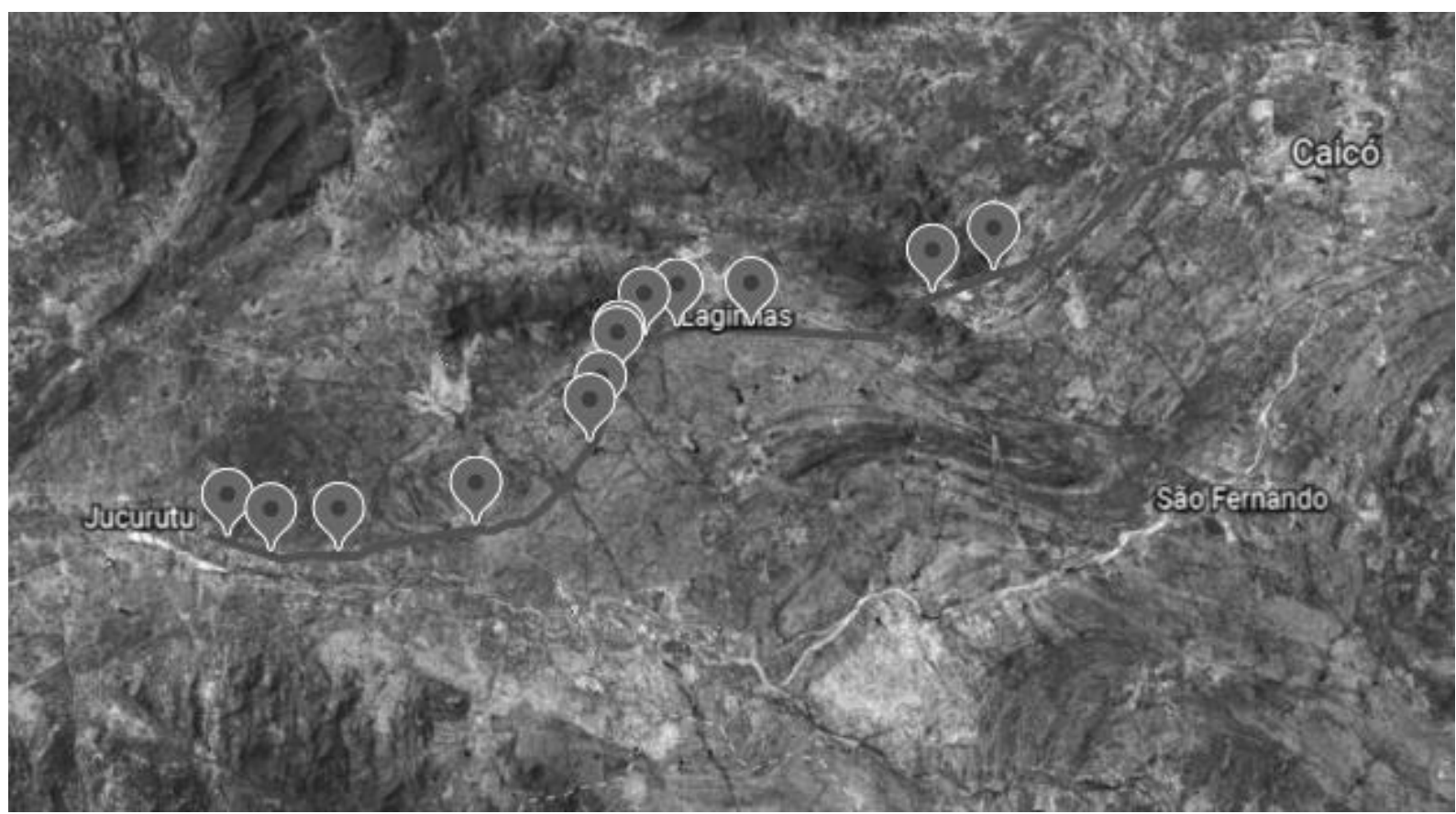

Figura 4: Mapa de situação das pontes visitadas. Google Earth (2019).

\subsubsection{Caracterização das pontes pesquisadas}

Segundo os moradores locais, até meados dos anos 70, a rodovia que interligava as cidades de Caicó e Jucurutu, ambas no RN, não eram pavimentadas. Ainda no século XX, com a difusão do automóvel e a consequente urbanização da sociedade, foram se fazendo necessárias inúmeras transformações nas estradas de todo o estado. Devido à importância logística da RN 118 na região, houve a necessidade da implementação de melhorias na rodovia, acomodando o tráfego cada vez mais intenso de veículos. Então, após anos de descaso, os governantes resolveram solicitar a construção de obras destinadas para a população.

Assim como a pavimentação das estradas, em virtude do terreno e da existência de bacias de água na região, foram necessárias a construção de pontes para sobrepor os obstáculos. Segundo os arquivos fornecidos pelo Departamento de Estradas de Rodagem do Rio Grande do Norte - DER RN existem 21 pontes no trajeto especificado, todas são obras em concreto armado.

Para classificação das pontes pesquisadas, neste trabalho utilizou-se a classificação de Marchetti (2017), em que se enumerou as pontes de acordo com sua extensão. No quadro 1, pode-se observar dados referentes a localização, extensão e largura das pontes pesquisadas, enumerando as Obras de Artes Especiais - OAE's de acordo com sua sequência na rodovia, Ponte 1 - P1; Ponte 2 - P2; Ponte 3-P3; Ponte 4-P4; Ponte 5 - P5; Ponte 6 - P6; Ponte 7 - P7; Ponte 8 - P8; Ponte 9 - P9; Ponte 10 - P10; Ponte 11 - P11; Ponte 12 - P12.

Quadro 1: Relação das pontes pesquisadas. Fonte: Adaptado DER - RN (2019).

\begin{tabular}{|c|c|r|r|}
\hline OAE N & Localização & Extensão (m) & Largura (m) \\
\hline P1 & Km 153,99 & 10 & 10,30 \\
\hline P2 & Km 155,74 & 9,50 & 10,10 \\
\hline P3 & Km 158,35 & 10 & 6,55 \\
\hline P4 & Km 163,74 & 10 & 10,10 \\
\hline P5 & Km 169,52 & 10 & 10 \\
\hline P6 & Km 170,47 & 6 & 9,20 \\
\hline P7 & Km 172,32 & 5 & 8,10 \\
\hline P8 & Km 171,55 & 10 & 9,80 \\
\hline
\end{tabular}




\begin{tabular}{|c|c|r|r|}
\hline P9 & Km 174,30 & 8 & 7,80 \\
\hline P10 & $K m ~ 175,60$ & 3,50 & 8,20 \\
\hline P11 & Km 178,45 & 2 & 7,30 \\
\hline P12 & Km 186,06 & 9 & 7,30 \\
\hline P13 & Km 188,49 & 6 & 7,60 \\
\hline
\end{tabular}

De acordo com a classificação de Marchetti (2017), todas a pontes visitadas são denominadas como pontilhões, visto que suas extensões vão de $2 \mathrm{~m}$ a $10 \mathrm{~m}$. Ainda descrevendo características, no croqui das pontes pode-se perceber alguns desníveis nas P2, P3, P4, P5 e P8, inseridos como métodos de drenagem natural da água do pavimento.
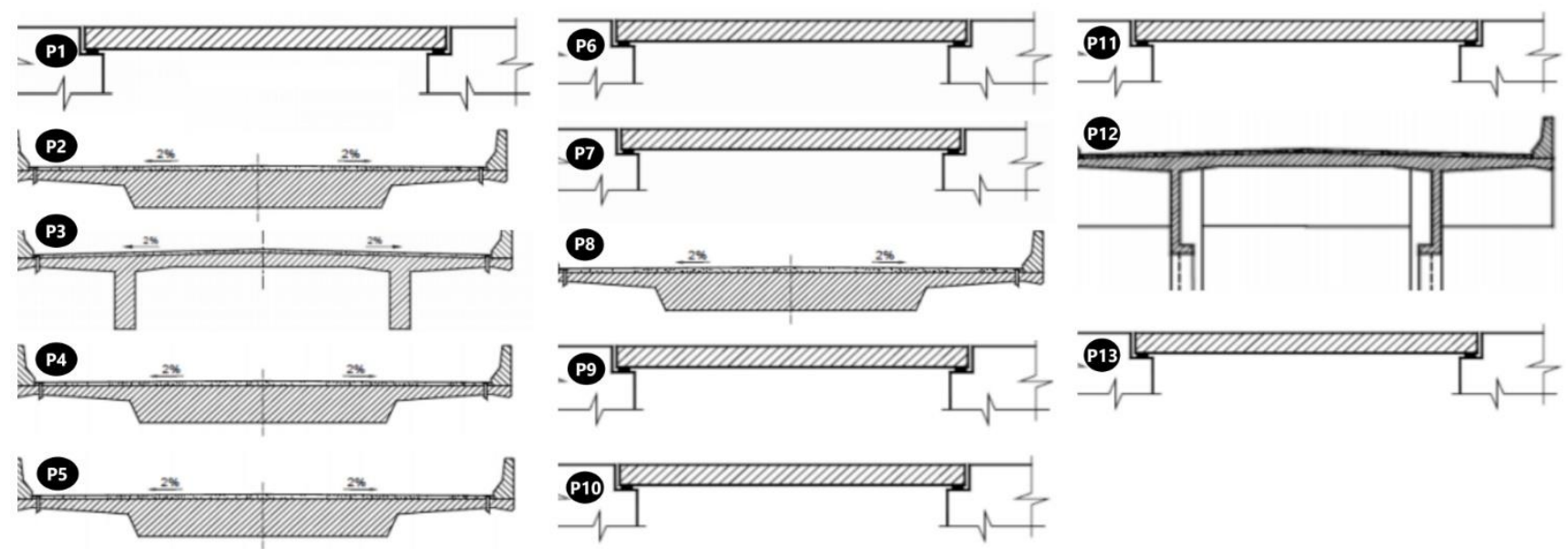

Figura 5: Croquis correspondentes as pontes vistoriadas. DER - RN (2019).

\section{RESULTADOS E DISCUSSÕES}

\subsection{Apresentação das condições gerais das pontes}

Com auxílio dos registros fotográficos foi realizado o levantamento das condições gerais das pontes pesquisadas. Foram observadas ao longo da pesquisa as seguintes anomalias: fissuras, manchas, corrosão das armaduras, desagregação e/ou segregação do concreto e eflorescências, assim como alguns erros de projetos. Como a análise foi feita apenas visualmente, foi possível relatar somente supostas causas da ocorrência das manifestações.

\subsubsection{Fissuração}

$\mathrm{Na}$ figura 6 apresenta-se fissuras/trincas nas vigas principais da P12. Foram detectadas várias fissuras/trincas em praticamente todas as pontes inspecionadas, as mesmas, embora pequenas, representam caminhos para a entrada de agentes agressivos.

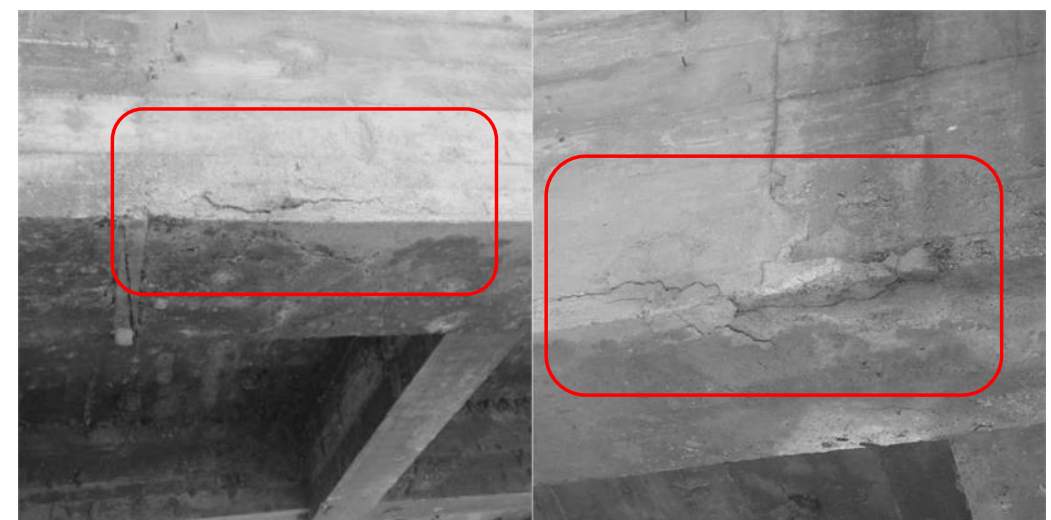

Figura 6: Aparecimento de fissuras na viga principal. Acervo do autor (2019).

Nos elementos de concreto armado convencional, a fissuração pode ser inevitável, em virtude de tensões de tração 
provocadas pela flexão, força cortante, torção e restrições à movimentação. Além disso, sua origem pode ser advinda de decomposição ou desagregação dos materiais componentes do concreto, excesso de carga, erros de projeto, erros de execução, sendo um fator determinante a exposição da estrutura a fenômenos naturais, que favorecem o desgaste do concreto, assim como uma distribuição irregular de tensões no interior da estrutura.

\subsubsection{Armaduras aparentes}

Na figura 7 apresenta-se esse tipo de anomalia na P8 e P12, ainda assim foi possível perceber em todas as pontes, porém algumas em estágios mais avançados que outras. Pode-se observar a exposição da armadura em alguns pontos das vigas longitudinais e transversais, assim como no seu tabuleiro.
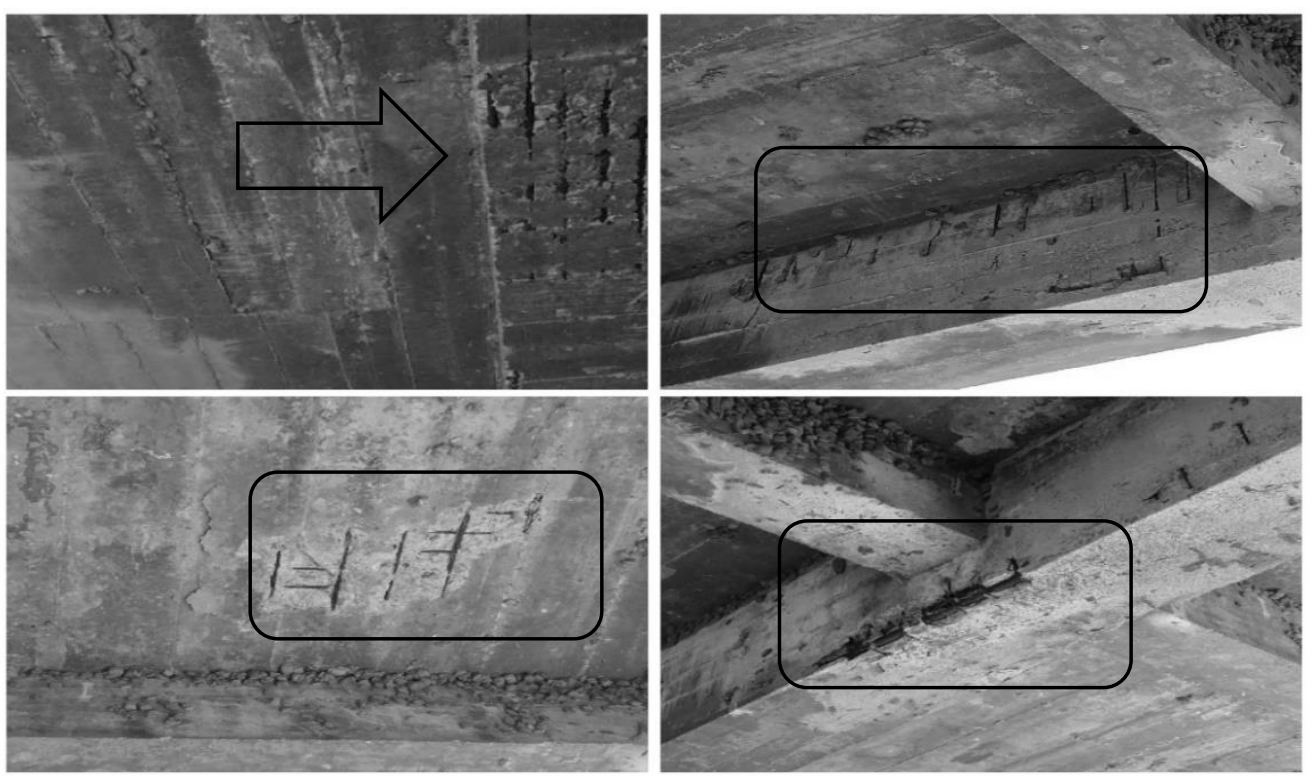

Figura 7: Exposição de armadura presente na superestrutura. Acervo do autor (2019).

Uma das possíveis causas dessa exposição da armadura seria o fato da existência de um ataque químico no local, mais precisamente da reação de carbonatação, deixando os agregados livre e causando assim o desplacamento do concreto. Ainda, pode ser causada pela perda de aderência entre o aço tensionado e o concreto. O fato de estarem expostas compromete a estrutura, pois ficam suscetíveis a corrosão, que reduz a resistência a flexão da viga. Então, torna-se necessária a realização de reparos na estrutura.

\subsubsection{Eflorescências}

Em virtude de muitas pontes do trecho estarem próximas a bacias de água, há ocorrência desse tipo de anomalia, visto que são ambientes com uma constante umidade. Ainda podem ser causadas pelo carreamento dos compostos hidratados do cimento, assim como a ausência de pingadeira, juntamente com o tubo de drenagem demasiadamente curto, fazendo com que a água proveniente da chuva penetre no pavimento. 


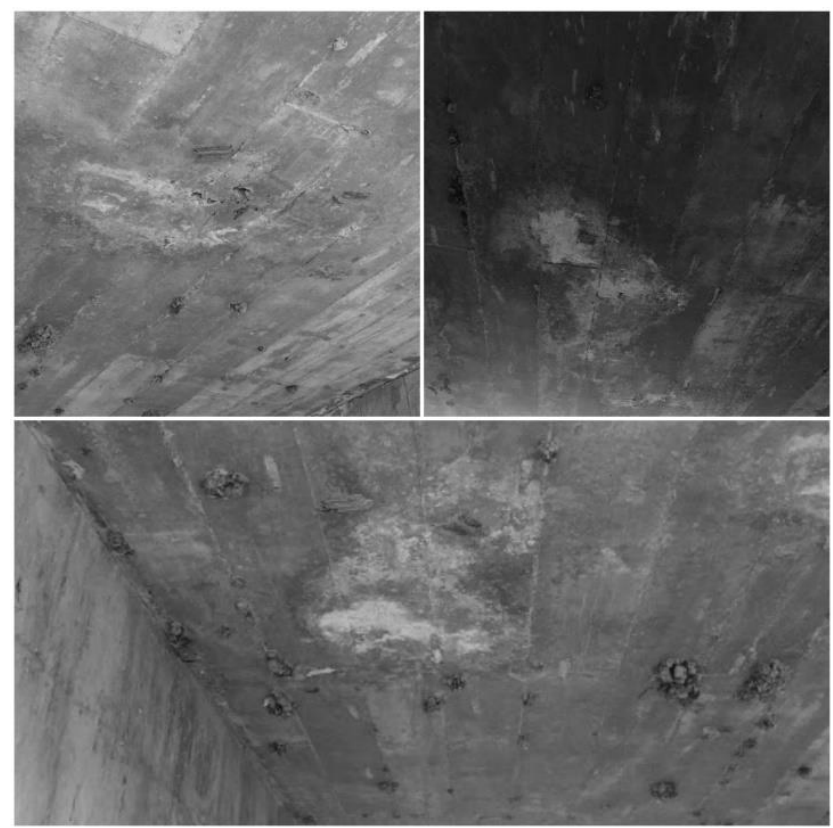

Figura 8: Manifestações patológicas do tipo eflorescência. Acervo do autor (2019).

Assim como na superestrutura, é perceptível o surgimento de eflorescências na mesoestrutura. Entretanto, só foi possível notar esse fenômeno em apenas duas pontes, P2 e P5. Diferente das outras pontes visitadas, nestas duas, há bastante água embaixo da estrutura, aumentando assim a probabilidade de ocorrer essa anomalia.

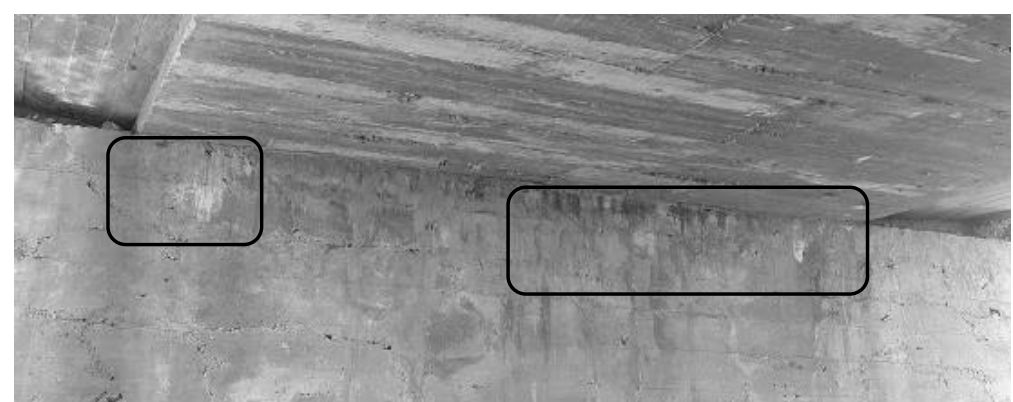

Figura 9: Aparecimento de eflorescência na mesoestrutura. Acervo do autor (2019).

\subsubsection{Sistema de drenagem}

O sistema de drenagem é presente nas P1, P2, P3, P4, P5, P8, P9 e P12, ainda assim, é considerado deficiente. A patologia é causada pelo pequeno comprimento do tubo de drenagem que, em vez de propiciar o escoamento correto da água do pavimento, dando maior vida útil a obra, causa problemas nas vigas inferiores.

Na figura 14, apresenta-se a P12, sendo possível perceber que a ação contínua da água que escorre em seu entorno desagrega o concreto, este com um cobrimento pequeno, expondo a armadura ao meio agressivo, causando danos ao material. Esse problema ainda pode acarretar outras manifestações patológicas. 


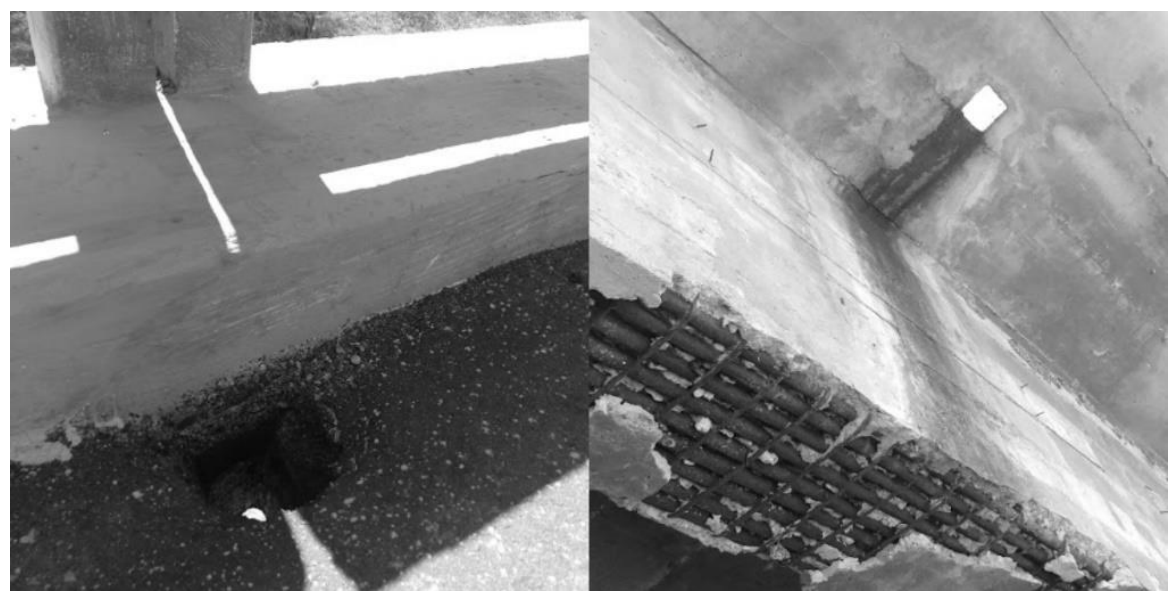

Figura 10: Problema decorrente de um sistema de drenagem ineficiente. Acervo do autor (2019).

\subsubsection{Guarda-corpos}

Levando em consideração de maneira geral, os guarda-corpos encontram-se em bom estado, apresentando apenas leves fissuras e manchas. Porém em algumas obras de arte, como a P9 o elemento de proteção não é presente. O guarda-corpo garante a segurança ao usuário da rodovia caso aconteça algum acidente. Na figura 11 pode-se perceber o risco que se corre quando da ausência do guarda-corpo, visto que a altura pode ser fatal em algum evento danoso.

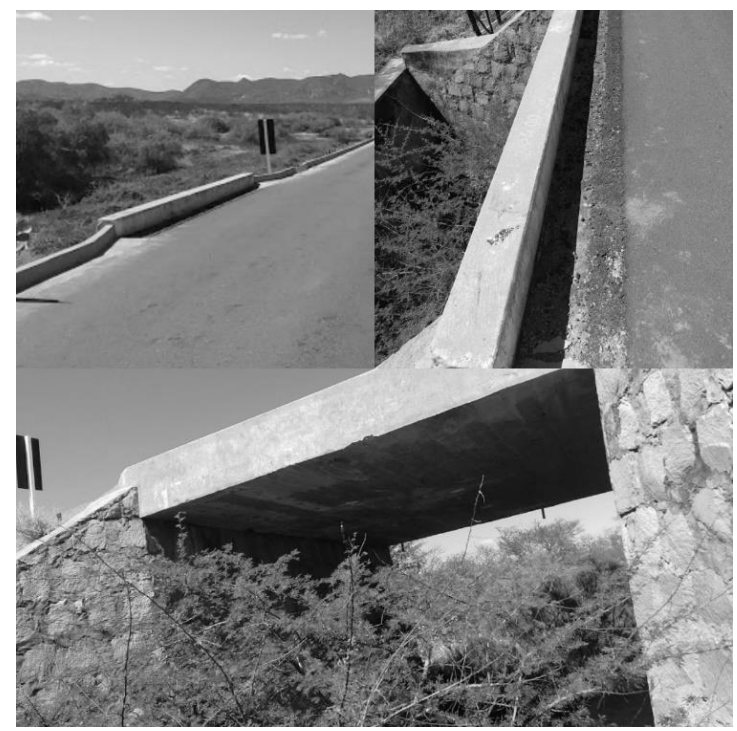

Figura 11: Ausência de guarda-corpo. Acervo do autor (2019).

\subsubsection{Juntas de dilatação}

A RN 118 passou recentemente por um recapeamento na pista, em virtude disso, e somando a execução sem a orientação devida, todas as juntas de dilatação encontram-se cobertas pelo pavimento. Apenas com a inspeção visual não é possível detectar se há algum tipo de acúmulo de detritos ou um alinhamento inadequado que possa causar a danificação e ineficiência das juntas. Como ilustrado na figura 12 . 


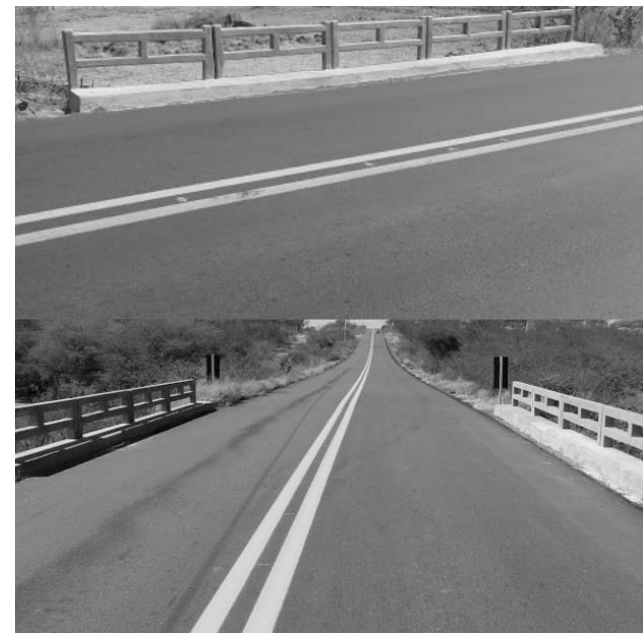

Figura 12: Juntas de dilatação cobertas pelo pavimento. Acervo do autor (2019).

\section{CONSIDERAÇÕES FINAIS}

Esse trabalho teve como objetivo principal realizar um levantamento das condições gerais das pontes da RN 118, trecho entre Caicó - RN e Jucurutu - RN. Diante do exposto e das condições de realização do trabalho foi possível deixar claro que as pontes apresentam uma grande incidência de manifestações patológicas em sua estrutura como um todo. Porém, apesar dos resultados, podemos afirmar que a situação poderia ser bem menos satisfatória, visto que as pontes não apresentam uma rotina de inspeção e manutenção preventiva. Além disso, há o fato de serem obras de arte antigas, com muito tempo de uso.

Com a vistoria no local podemos citar a ocorrência mais frequente de fissuras, rachaduras, eflorescência, manchas, exposição e corrosão das armaduras. É perceptível que a durabilidade das estruturas de concreto armado é diretamente afetada e influenciada pela água, enquanto agente deteriorante e veículo de transporte de substâncias agressivas. Ainda é possível perceber que há problemas que podem piorar essas manifestações patológicas. $\mathrm{O}$ fato de as juntas de dilatação estarem cobertas pela pista acarretará em prejuízos na estrutura, sendo o aparecimento de trincas transversais no pavimento uma resposta imediata da estrutura, aberturas propícias para infiltrações.

Em grande parte das OAE’s há eflorescências, que poderia ser evitada se os concretos usados na construção das estruturas fossem mais impermeáveis, sendo capazes de neutralizar a passagem da água para a laje das estruturas, somam-se ainda as deficiências no sistema de drenagem de águas pluviais.

A grande maioria dos problemas encontrados nas pontes poderiam ser evitados com inspeções e manutenções, que, segundo os arquivos do DER - RN deveriam ocorrer de três em três anos, porém é notório que não existe uma política de fiscalização para tais ações. Ainda, pode-se considerar que pequenos reparos possibilitariam o aumento da vida útil da obra.

\section{REFERÊNCIAS BIBLIOGRÁFICAS}

ABNT NBR 9575: Seleção e projeto de impermeabilização. Rio de Janeiro, 2003.

BERTOLINI, Luca. Materiais de construção: patologia, reabilitação, prevenção. São Paulo: Oficina de Texto, 2014. $414 \mathrm{p}$.

CURCIO, Ronald Cristhian de Lima. PONTES RODOVIÁRIAS: Levantamento das principais patologias estruturais. 2008. 56 f. TCC (Graduação) - Curso de Engenharia Civil, Universidade São Francisco, Itatiba, 2008.

DNIT. (2004). Manual de Inspeção de Pontes Rodoviárias. Departamento Nacional de Infraestrutura de Transportes. Diretoria de Planejamento e Pesquisa, Rio de Janeiro.

DNIT. (2010). Manual de Recuperação de Pontes e Viadutos Rodoviários. Departamento Nacional de Infraestrutura de Transportes. Diretoria Executiva, Rio de Janeiro. 
EL DEBS, M. K.; TAKEYA, T. Pontes de Concreto. São Carlos, USP - Universidade São Paulo, 2009. Notas de aula. FUSCO, P.B. Tecnologia do concreto estrutural: Tópicos aplicados a componentes, durabilidade, resistência mecânica, corrosão e compressão. São Paulo, Pini, 2008.

GiOVAnnetti, Ana Carolina V. P. AVAliAÇÃo DO ESTAdo DE CONSERVAÇÃO DE PONTES ESTUDO DE CASO / Ana Carolina V. P. Giovannetti; orientador, Roberto Caldas de A. Pinto - Florianópolis, SC, 2014. $130 \mathrm{p}$.

HELENE, Paulo R. L. Manual para Reparo, Reforço e Proteção de Estruturas de Concreto. 2a ed. São Paulo: Pini, 1992.

MARCHETTI, Osvaldemar. Pontes de concreto armado. São Paulo: Blucher, 2017. 237 p.

MENDES, Paulo de Tarso Cronemberger. Contribuições para um modelo de gestão de pontes de concreto aplicado à rede de rodovias brasileiras. P. T. C. Mendes - São Paulo, 2019. 235 p.

NEVILLE, A.M . Propriedades do concreto. 5. ed. Porto Alegre: Bookman, 2016. 888 p.

PIANCASTELLI, E.M. - Patologia, Recuperação e Reforço de Estruturas de

Concreto Armado -

Ed. Depto. Estruturas da EEUFMG - 1997 - 160p. - Apostila para Curso de Extensão

PINTAN, Natália Müller. Manifestações patológicas e estudo da corrosão presente em pontes do Recife. Recife: UPE, 2013. 173 p. Dissertação (Mestrado). Escola Politécnica da Universidade de Pernambuco. Programa de PósGraduação em Engenharia Civil. Recife.

SOUZA, V. C.; RIPPER, T. Patologia, recuperação e reforço de estruturas de concreto. São Paulo: Pini, 1998. 255 p.

VITÓRIO, J. A. P. Vistorias, Conservação e Gestão de Pontes e Viadutos de Concreto. Anais do $48^{\circ}$ Congresso Brasileiro do Concreto, 2006.

VITÓRIO, José Afonso Pereira. Pontes rodoviárias: fundamentos, conservação e gestão. Recife, CREA-PE, 2002.

ALVES, Lauro Ferenzini. OBRAS-DE-ARTE ESPECIAIS BR-267/MG: PATOLOGIAS $x$ FATORES INFLUENTES. 2012. 86 f. Tese (Graduação) - Curso de Engenharia Civil, Universidade Federal de Juiz de Fora, Juiz de Fora, 2012. 